\title{
Entre lar e Igreja: A Educação de mulheres e as Congregações religiosas na Amazônia Paraense (1900-1927)
}

\author{
Between home and the church: Women's \\ Education and religious congregations in the \\ Paraense Amazon (1900-1927) \\ Entre hogar y la Iglesia: La Educación de las \\ mujeres y las Congregaciones religiosas en la \\ Amazonia Paraense (1900-1927) \\ Tayana Helena Cunha Silva (iD ${ }^{a}$ \\ LaURa Maria Silva Araújo Alves (iD $b$
}

\section{Resumo}

Este artigo tem como cenário a educação mulheres nas primeiras décadas do século XX na Amazônia paraense. As congregações religiosas que atuaram em instituições femininas no Pará administraram instituições educativas que abrigaram, instruíram e educaram meninas para ajudar a construir o Pará republicano. Pretende-se analisar as ações e práticas educativas das congregações Filhas de Sant'ana e Irmãs de Santa Doroteia. De cunho documental, o corpus da pesquisa é constituído dos jornais católicos A Palavra e A Boa Nova, mensagens dos

\footnotetext{
a Universidade Federal do Pará (UFPA), Belém, Pará, Brasil. Mestre em Educação, e-mail: tayanacunhahcs@gmail.com

b Universidade Federal do Pará (UFPA), Belém, Pará, Brasil. Pós-Doutora em Educação, e-mail: laura_alves@uol.com.br
} 
governadores do estado do Pará e o relatório do Instituto Gentil Bittencourt. Os resultados indicam que as meninas educadas pelas duas congregações eram instruídas nas habilidades femininas para se tornassem mães de família e mulheres preparadas para o casamento. As congregações atenderam aos anseios das oligarquias em Belém, no propósito de disseminar uma formação educativa feminina em asilos, colégios e internatos, funcionando a partir da parceria entre Igreja e Estado. As ações das Congregações Filhas de Sant'ana e Irmãs Doroteias, na Amazônia paraense no período da Belle Époque, foram fundamentais para a formação de mulheres integras, prendadas e com valores morais cristãos. Devido a existência de vários espaços considerados "perigosos" para as mulheres, a atuação das congregações evitaram que elas caíssem no abandono, criminalidade e prostituição. A educação defendida pelas congregações teriam a missão de formar mulheres de modelo para os filhos e exemplo para os maridos e úteis à sociedade paraense.

Palavras-chave: Educação. Mulheres. Congregações. Amazônia Paraense

\begin{abstract}
This paper focuses on the education of women in the first decades of the twentieth century in the Amazon of Pará. The religious congregations that served in women's institutions in Pará administered educational institutions that housed, instructed and educated girls based on ideals republican in Pará. It is intend to analyze the educational actions and practices of the congregations Filhas de Sant'ana and Irmãs de Santa Doroteia. Documentary in nature, the research corpus consists of the Catholic newspapers A Palavra and A Boa Nova, messages from the governors of the state of Pará and the report by the Gentil Bittencourt Institute. The results indicate that girls educated by the two congregations were instructed in women's skills to become mothers of families and women prepared for marriage. The congregations responded to the wishes of the oligarchies in Belém with the purpose of disseminating a female educational formation in nursing homes, schools and boarding schools, working from the partnership between Church and State. The actions of the Congregations Filhas de Sant'ana and Irmãs Doroteias, in the Paraense Amazon during the Belle Époque period, were fundamental for the formation of women whole, arrested and with Christian moral values. Due to the existence of several spaces considered "dangerous" for women, the work of the congregations prevented them from falling into abandonment, crime and prostitution. The education advocated by the congregations would have the mission of forming women who are role models for their children and role models for their husbands and useful to society in Pará.
\end{abstract}

Keywords: Education. Women. Congregations, Paraense Amazon. 


\section{Resumen}

Este artículo tiene como escenario la educación de las mujeres en las primeras décadas del siglo XX en la Amazonia paraense. Las congregaciones religiosas que actuaron en instituciones femeninas en Pará administraron instituciones educativas que albergaron, instruyeron y educaron a niñas para ayudar a construir el Pará republicano. Se pretende analizar las acciones y prácticas educativas de las congregaciones Filhas de Sant' ana y Irmãs de Santa Doroteia. De cuño documental, el corpus de la investigación está constituido por los periódicos católicos A Palavra y A Boa Nova, mensajes de los gobernadores del estado de Pará y el informe del Instituto Gentil Bittencourt. Los resultados indican que las niñas educadas por las dos congregaciones eran instruidas en las habilidades femeninas para convertirse en madres de familia y mujeres preparadas para el matrimonio. Las congregaciones atendieron los anhelos de las oligarquías en Belém con el fin de difundir una formación educativa femenina en asilos, colegios e internados, funcionando a partir de la asociación entre Iglesia y Estado. Las acciones de las Congregaciones Filhas de Sant'ana y Irmãs Doroteias, en la Amazonia paraense en el período de la Belle Époque, fueron fundamentales para la formación de mujeres integrales, sostenidas y con valores morales cristianos. Debido a la existencia de varios espacios considerados "peligrosos" para las mujeres, la actuación de las congregaciones evitaron que ellas cayeran en el abandono, criminalidad y prostitución. La educación defendida por las congregaciones tendría la misión de formar mujeres de modelo para los hijos y ejemplo para los maridos y útiles a la sociedad paraense.

Palabras clave: Educación. Mujeres. Congregaciones. Amazonia Paraense.

\section{Introdução}

No Orphelinato preparam-se mães de família, laboriosas, modestas e dignas, incutindose no animo das educandas os incomparáveis preceitos ensinados por Jesus Chisto, de par com o ensino de prendas domésticas [...]. A mulher, no entanto, não póde ficar circumscripta ao grandioso papel de ornamentação do lar. É necessário que ella seja, não só mãe de família tradicionalmente bôa e amavel, qual é a mulher brasileira,-mas também a companheira eficaz, de inteligência culta, que com o esposo compartilhe das luctas quotidianas, tornando menos fadigoso o trabalho d'aqueles. Estes conceitos fóros axiomáticos, aplicados ao Orphelinato, cuja aspiração mais nobre deve ser a existência honrada, mas laboriosa, das classes modestas" (p. 256).

O trecho acima é extraído do relatório de 1903 apresentado ao Conselho Municipal de Belém ${ }^{1}$ na sessão de 15 de novembro de 1904, pelo intendente

\footnotetext{
${ }^{1}$ Relatório O Municipio de Belém (1903) apresentado ao Conselho Municipal de Belém na sessão de 15 de novembro de 1904, pelo intendente Senador Antonio José Lemos, em 1903.
} 
Antônio José de Lemos², que ilustra bem o universo da educação de meninas no Orphelinato Paraense ${ }^{3}$. Companheira eficaz, de inteligência culta e para ser mãe de família eram as qualidades desenvolvidas na educação de meninas órfãs do Orphelinato Paraense. Indubitavelmente, essas seriam as principais características do modelo pedagógico da educação feminina no interior da instituição. A educanda órfã era preparada para se tornar mãe de família, com forte inclinação religiosas e habilitadas nas prendas domésticas.

No início do século XX, Belém vivenciava o auge da economia da borracha na Amazônia que desencadeava um movimento de modernidade à região. Eram tempos em que o comércio gomifero na Amazônia proporcionava a elite paraense novos e refinados valores culturais, principalmente mudanças de vida e de comportamentos arquitetados à moda europeia. O requinte estimulado pela Belle Époquet reforçava a formação de mulheres educadas para atender às demandas dessa

\footnotetext{
${ }^{2}$ Antônio José de Lemos nasceu em São Luís, no Maranhão, em 17 de dezembro 1843, e faleceu no Rio de Janeiro em 2 de outubro de 1913. É considerado o mais importante intendente de Belém de 1897 a 1911. Lemos foi o principal responsável pela transformação sanitária da cidade no início do século XX. Modernizou a cidade de Belém dando-lhe um ar de bela metrópole nos trópicos. Sua carreira política começou em 1885, no Partido Liberal que o elegeu deputado provincial. Quando ocorreu a Proclamação da República, Lemos exercia o cargo de presidente da Câmara Municipal, também foi jornalista, político e administrador. Fez da Província do Pará o melhor jornal que circulava na capital do Pará. Sua personalidade demonstrava um homem metódico, organizado e ambicioso. Diferenciou-se dos velhos políticos em razão da sua proximidade com o homem da terra, dos considerados eleitores "rudes e grossos".

${ }^{3}$ O Orphelinato Paraense foi fundado 1893 a partir da iniciativa de algumas famílias da elite paraense, preocupada principalmente com o crescimento acelerado da populacional e pelo surgimento de pessoas indesejadas e de órfãos desamparadas que não contavam com nenhuma forma de subsistência. Para minimizar o desconforto social que a elite paraense sentia com as órfãs desamparadas, elas se tornaram alvo de preocupação do executivo municipal que desejava criar uma instituição que lhes dessem além de uma saudável moradia, uma consistente educação de práticas doméstica, instrução literária e as primeiras letras. Enfim, a referida instituição municipal procurava-se em proteger, educar, instruir as órfãs sob a égide de uma formação feminina, para se tornarem boas esposas e mães de família. O orphelinato Paraense foi se delineando aquele que seria um dos mais importantes projetos de cunho caritativo, pelo menos durante as primeiras décadas do século seguinte.

${ }^{4}$ A expressão Belle Époque demarca um período, dito de ouro, que simbolizou a partir da segunda metade do século XIX, e a primeira década do século XX, o impulsionamento do progresso, aumento de produção industrial, avanço tecnológico, urbanização de cidades e proliferação de novas tendências nas artes, educação e costumes na Europa, Estados Unidos e Brasil. A sagração de Belle Époque mundial foi marcada por toda uma conjuntura voltada para o chamado progresso e civilidade. No caso da Amazônia paraense, as
} 
nova elite local composta por seringalistas, profissionais liberais, financistas, comerciantes e fazendeiros. A mulher passava a ter um papel importante para a disseminação dessa modernidade compreendida como importante para a consolidação dessa nova elite. Cabia a mulher o espaço privado do lar. Contudo, não se aplicava a uma efetiva participação feminina nos espaços público, pelo contrário, quanto menor a atuação das mulheres no interior desses espaços, melhor as elites se sentiam organizadas. Desejava-se uma capital moderna, com hábitos e costumes parisienses, mas essa modernidade não conseguia acabar com concepções conservadoras a respeito das mulheres.

A face conservadora era dominado integramente pela Igreja Católica no Pará, que concebia a mulher como uma figura que tinha a missão de ser mãe de família, exemplo de esposa, religiosa, habilidosa em trabalhos manuais, além de boa e amável, eficaz companheira, de inteligência culta para acompanhar o esposo e com uma existência honrada. A educação feminina se concentrava em formar a mulher para o universo doméstico baseado em valores morais e religiosos conservadores. $\mathrm{O}$ intuito era formar esmeradas esposas e mães que tivessem condutas morais irrepreensíveis. A representação simbólica da mulher frágil, abnegada, afetiva, mas assexuada, vigilante do lar, boa esposa e mãe reforçavam a imagem conservadora da sociedade paraense e da Igreja Católica na Amazônia. Segundo Almeida (2014), em razão da velha compreensão patriarcal de que a mulher era tida como sexo frágil, a desobrigava de ter uma atividade laboral, a não ser que tivesse relação com sua natureza maternal.

A educação de prendas doméstica ${ }^{5}$, desenvolvidas pelas instituições criadas na capital do Pará, tinham a tarefa de educar as meninas dentro dos princípios da

riquezas advindas da extração do látex nas seringueiras da floresta amazônica promoveram intensas transformações no cenário das artes, na cultura, arquitetura e na urbanização da cidade de Belém. Toda a transformação foi realizada pelo Intendente Antônio Lemos, que se inspirou nos modelos das grandes cidades europeias. Além da urbanização, embelezamento da cidade e mudanças na arquitetura, Lemos estabeleceu medidas de controle dos hábitos da população com o objetivo de evitar propagação de doenças epidêmicas e a proliferação do alcoolismo, delinquência, mendicância e prostituição (SARGES, 2010).

${ }^{5} \mathrm{~A}$ educação prendas domésticas era o modelo de educação destinada às mulheres e matérias obrigatórias nos currículos escolares de formação feminina na cidade de Belém. O espaço doméstico do lar deveria ser ocupado pelas mulheres com a tarefa de "esposa- 
moral e da fé cristã a fim de conservá-las das chamadas tentações da modernidade, a qual era vista com reservas entre religiosos e os indivíduos mais conservadores da sociedade paraense. Todo este cuidado era reforçado na educação de meninas, as quais deveriam ser educadas para o casamento e preservadas para manter sua pureza e se tornarem boas mães de família. Enfim, na Amazônia paraense o "projeto educacional tinha por objetivo preparar trabalhadores para colonizar a região e esposas para a constituição de famílias dentro dos moldes cristãos" (RIZZINI; SCHUELER, 2016, p. 77).

Dessa forma, as congregações religiosas que atuaram em instituições femininas se colocaram como frente relevante para esta ação ao administrar instituições educativas que abrigaram e instruíram meninas, para que se adquirissem a condição de mulheres e pudessem ajudar a construir a República paraense. Neste cenário republicano, boa parte da população feminina tinha pouco ou nenhum domínio da escrita e leitura, além de conhecimentos em outras áreas, pois sua formação centrava-se no universo doméstico, com habilidades para cuidar dos filhos e da casa (ALMEIDA, 1998).

Neste sentido, as congregações das Filhas de Sant'ana ${ }^{7}$ e Irmãs de Santa Dorotéia ${ }^{8}$ educaram as meninas da capital paraense para se tornarem exemplos de

dona-de-casa-mãe-de-família. Desde cedo a menina era formada para se tornar esmeradas esposas e futuras mães, que fossem portadoras de valores morais respeitados. Cabia, então, às instituições educativas uma formação primária arquitetada na educação moral e tarefas domésticas, com o objetivo de transformá-las em boas donas de casa, habilitadas aos afazeres do lar.

${ }^{6} \mathrm{O}$ projeto de uma cidade moderna e civilizada que a elite paraense tanto desejava no início do século XX buscava adequar a população aos moldes europeus de urbanização e civilização. Contudo, tal modelo se chocava diante de um considerável contingente de meninas abandonadas, pobres ou órfãs. O recolhimento de meninas em instituições sob os auspícios da Municipalidade adequava aos anseios das autoridades locais, que passavam a cuidar das pobres órfãos para obter uma formação feminina apropriada.

${ }^{7}$ A congregação religiosa das Filhas de Sant'ana foi fundada em 08 de dezembro de 1866 na cidade de Piacenza, na Itália, com o objetivo de cuidar dos doentes desabrigadas em hospitais e abrigos. O grupo religioso foi criado por Madre Rosa Gattorno, que nasceu em Gênova também na Itália, em 1831. Essa religiosa foi criada dentro dos princípios cristãos católicos os quais estiveram presentes em toda a sua formação até a idade adulta quando fundou a referida congregação. Inicialmente, a congregação foi batizada de Filhas de Imaculada e Mínimas de São Francisco. Posteriormente, estas religiosas passaram a ser 
mulheres prendadas e virtuosas, bem como instruídas dentro dos valores cívicos e de amor à pátria para que, de certa maneira, colaborassem na construção da pátria republicana. Mas, afinal, questionamos: Como as congregações Filhas de Sant'ana e Irmãs de Santa Dorotéia desenvolveram a educação de mulheres? Em que medida as congregações Filhas de Sant'ana e Irmãs de Santa Dorotéia atenderam aos anseios da elite paraense na formação de mulheres? Nessa direção, indicamos como objetivo principal deste estudo analisar a educação feminina na cidade de Belém, nas primeiras décadas do século XX, a partir da rotina educativa das instituições geridas pelas congregações das Filhas de Sant'ana e Irmãs de Santa Dorotéia. De caráter documental, este estudo foi construído a partir de fontes como: jornais católicos "A Palavra" e "A Boa Nova", Relatório de Mensagens dos governadores do Estado do Pará no referido período histórico, assim como o relatório de atividades do Instituto Gentil Bittencourt do ano de 19099 .

A análise das fontes foi amparada a partir de autores da História da Educação nacional como Almeida (1998; 2014), Aquino (2014), Bittencourt (2017), Leonardi (2016), Rizzini; Rizzini (2004) Marcílio (1998), Rago (1985); e de autores da História

chamadas de Sant'tana em razão da aparição de Nossa Senhora de Sant'ana para a Madre Rosa Gattorno (JUBILEU, 2009).

${ }^{8}$ A fundadora da congregação das Irmãs de Santa Dorotéia da Fraassinetti nasceu em 1809 na cidade de Gênova na Itália. Tendo a fé como princípio central, as religiosas Dorotéias destacavam três valores essenciais: Caridade, Obediência e Simplicidade. A caridade para a fundadora das religiosas Dorotéias representavam o acolhimento de Deus na figura dos mais pobres; a obediência, as raízes educativas; a simplicidade como intuição pedagógica. As instituições educativas dirigidas pelas Irmãs Dorotéias pregam a evangelização por meio da educação como também contemplam neste processo formativo os valores éticos e cristãos tendo como referências os ensinamentos da Igreja.

${ }^{9}$ A busca pelo corpus documental da pesquisa foi realizada em dois locais. O primeiro se trata ao Arquivo Público do Estado do Pará (Apep), onde encontramos o relatório de atividades do Instituto Gentil Bittencourt do ano de 1909 e as mensagens dos governadores do Estado do Pará, onde estes relatavam a situação estadual sobre diversos setores como economia, obras públicas, e Educação. Em cada mensagem, o administrador estadual informava a assembleia legislativa sobre as ações desenvolvidas para o funcionamento dos ensinos primário, secundário e superior. O segundo local de busca documental deste estudo foi a Cúria Metropolitana Arquidiocese de Belém, onde foram encontrados os jornais católicos $A$ Palavra e $A$ Boa Nova, que veiculavam notícias sobre a igreja católica no Pará, assim como a respeito do cotidiano das instituições educativas administradas por congregações religiosas, onde o cotidiano educativo liderado pelas religiosas de Sant'ana e Santa Dorotéia também foram identificados. 
da Educação na Amazônia como Costa; França (2016), França (2007). Bezerra Neto (1998), Veríssimo (1906). Pimenta; França (2015), Sabino (2018), Rizzini; Schueler (2016) e Sarges (2010) que discutem sobre as questões da educação feminina, atividades da Igreja católica na educação brasileira e das práticas educativas republicanas no Pará.

O artigo está dividido em três momentos. No primeiro há uma discussão histórica sobre a educação feminina no cenário do Pará republicano e a relação da Igreja com os interesses das oligarquias no Pará. Posteriormente, há uma análise das ações e do ideário educativo das congregações religiosas Filhas de Sant'ana e Irmãs de Santa Dorotéia na Amazônia paraense.

\section{A Educação feminina no contexto no Pará Republicano}

O advento da República no Pará trouxe consigo um projeto de modernização e urbanização que propunha modificar a sociedade paraense com o intuito de equipará-la aos parâmetros de civilidade europeia. O Pará estava envolvido em todo esse processo de modernidade que ocorria de modo nacional buscando alterações na estrutura física das cidades, que também refletiu em transformações nas mentalidades da população local, sobretudo da capital, que incentivada a adquirir novos comportamentos ou até mesmo concepções (SARGES, 2010).

A capital paraense sofre grandes transformações na época do boom gomífero, tornou-se um lugar agitado com características mais europeia do que brasileira, pois foi dominada por um francesismo que produziu uma ligação da cidade com a Europa. Belém passou a ser uma das cidades brasileira na vanguarda na execução da modernidade ao lado de São Paulo e Rio de Janeiro e, nesta lógica, a capital paraense vivenciou as modificações inerentes à modernidade a partir de ações do poder público que viabilizou grande parte desse movimento de renovação no governo do intendente Antônio Lemos. Alavancadas pela modernidade e pelo auge da exploração da borracha, estas mudanças possibilitaram a instalação de igrejas, palacetes, grandes prédios públicos, redes sanitárias públicas, entre outros empreendimentos inspirados e arquitetados no modelo francês de urbanização (SARGES, 2010). 
As transformações provindas da modernidade, além de perpassarem por fatores estruturais também atendiam às mentalidades, uma vez que para tanto se fazia necessário controlar e modelar a população mais pobre com a finalidade de condicioná-las às exigências dos novos tempos. Para atingir o patamar de civilidade, já que a região Norte era considerada atrasada e com um povo ignorante do ponto de vista educacional, os governantes e reformadores do Pará defenderam que a educação seria um caminho para regenerar a sociedade que ao ser instruída, elevaria o nível do país, assim configurando uma região.

Embora com um cenário de grande prosperidade em Belém devido o comércio da borracha, a população aumentava consideravelmente e as mulheres na sua maioria pobre e analfabeta. As mulheres abastadas desempenhavam atividades domésticas e de organização do lar, já as mulheres pobres e analfabetas desempenhavam atividades como lavadeiras, quituteiras, costureiras, cozinheiras, tacacazeiras, vendedoras de flores etc. (SARGES, 2010). Contudo, cabia a mulher brasileira, como a de qualquer nação civilizada, em primeiro lugar, a missão de ser mãe, esposa, companheira, amiga e conselheira de seu marido; e em segundo lugar, a missão de mestra dos seus filhos, dona e reguladora da economia do lar (VERISSÍMO, 1906, p. 152-153).

A educação seria a ferramenta para adequar os cidadãos ao ideário da nova pátria ${ }^{10}$. O ensino primário seria o caminho mais indicado por conta de que quanto mais cedo se começasse a incutir os valores cívicos e de engrandecimento da pátria nos indivíduos, melhor seria para constituir uma população civilizada e patriota. Neste cenário estava a educação de mulheres, que deveria privilegiar a formação de prendas doméstica e de qualidades para administrar o lar e cuidar da família. Com o papel de boa mãe e esposa obediente, as mulheres precisavam receber certa instrução para serem úteis a essa nova elite formada na capital do Pará. Nessa direção, Hahner (2018) destaca que com o surgimento do ideário republicano o qual pressupunha ideais de progresso e exaltação da nação, a mulher passou a ser notada como uma figura de considerável importância, no sentido de poder colaborar na educação dos

\footnotetext{
${ }^{10} \mathrm{O}$ analfabetismo entre mulheres era elevado no contexto paraense, evidenciando que a realidade da formação feminina não estava muito distante da conjuntura nacional. Uma razão que pode elucidar esta questão se trata do controle social exercido na mulher por parte da sociedade local.
} 
filhos para que fossem bons cidadãos para a República no Pará. Segundo Veríssimo (1906), a educação da mulher brasileira era fruto da herança cultural portuguesa com a política do recolhimento religioso e uma vida de clausura, com as exigências do mundo moderno era necessário oferecer-lhe uma educação que a libertasse dessa submissão e dependência. Assim, a mulher deveria ser preparada de forma racional, com o objetivo de contribuir para uma formação moral do cidadão. Entretanto, essa preparação não a tirava da condição de subserviência ao marido e a clausura do lar. Ou seja, ainda que como uma instrução, a sociedade considerava que "a mulher compete dar o tom à casa, ser a alma da família, das conversações, das diversões domésticas" (VERÍSSIMO, 1906, p. 155-157).

Por mais que este movimento de ampliação da participação da mulher na sociedade tenha dados os primeiros passos logo nos anos iniciais do século XX, Hahner (2018) alerta que a expansão da função feminina na prática não representou avanços expressivos, haja vista a premissa de que as atividades femininas não deveriam transpor os limites domésticos, que ainda vigoravam naquele período. Isto é, cabia a mulher o espaço da casa, ao mundo privado dos afazeres domésticos, dos cuidados dos filhos e de servir ao esposo.

Além da formação de prendas domésticas, permitia-se à educação primária na formação das futuras mães de família de modo que o ensino das lições primárias se tornaria fundamental na educação das meninas instruídas nas instituições femininas no Pará, sobretudo as meninas de famílias de condição financeira favorável.

A educação de mulheres no Pará seguia a mesma lógica formativa em curso a nível nacional, destacando a função feminina de ser boa mãe e esposa, porém sem desprezar as pretensões da modernidade que surgiram com a modernização da cidade de Belém, as quais pretendiam constituir um cidadão compatível com os anseios da nova conjuntura econômica da região. As escolas confessionais femininas, segundo Bezerra Neto (1998, p. 195), "paradoxalmente, possuíam um papel de grande importância como agentes construtores da hegemonia burguesa, haja vista que a percepção burguesa da figura da mulher coincidia com o ideal feminino postulado pela Igreja: a mulher, segundo o modelo mariano”. 
Esse modelo de educação destinada às mulheres no Pará foi desenvolvido nas instituições educativas dirigidas por congregações religiosas que se instalaram na região amazônica. A formação doméstica para mulheres era incentivado pela Igreja Católica e amplamente defendida pela elite local. De acordo com Aquino (2013), o processo de diáspora de ordens e congregações religiosas femininas para o Brasil teve o apoio eclesiástico ao conservantismo. As congregações deram início no surgimento de vários asilos, dispensários, escolas, orfanatos e hospitais, mantendo principalmente o caráter sagrado das ações assistenciais e educacionais. No mais, elas atuaram na formação feminina com o propósito de oferecer educação e espaço para as mulheres atuarem na vida pública. Enfim:

As ações dessas congregações contribuíram, de um lado, para o crescimento da educação no Brasil; e de outro, "para o início da transformação do papel social da mulher na sociedade brasileira, ainda que pelo viés conservador da moral católica, um 'feminismo católico' (AQUINO, 2013, p. 10).

A educação feminina nas instituições, sob a égide da direção e organização pedagógica das congregações religiosas em Belém, começava desde a infância, quando as meninas iniciavam o processo educativo dividido entre lições relativas aos misteres do seu gênero: aulas de bordado e costura, aulas do ensino primário, aulas de piano, canto e boas maneiras. Havia também uma sólida educação moral e literária. Essa educação esmerada não tinha o objetivo apenas de instrumentalizar as meninas em mulheres prendadas para atuar no espaço doméstico com o casamento, mas sim possibilitar utilizá-las nas casas de famílias como "filhas de criação" ou "damas de companhia".

A aliança construída entre a Igreja Católica ${ }^{11}$ e a oligarquia paraense, representada pela burguesia do comércio da borracha, estabeleceu condições favoráveis para a criação de instituições femininas através da fundação de asilos, colégios e institutos para mulheres e a administração da educação por congregações

\footnotetext{
${ }^{11}$ A influência da religião católica na constituição do indivíduo remete a uma prática executada desde o século XIX e persistente no século seguinte, ainda que a Igreja e estado estivessem dissociadas. No entanto, sobre o alinhamento dos comportamentos femininos, a Igreja foi a mais fundamental educadora que desde a infância instruía as meninas para a vida doméstica nas instituições educativas católicas, não confessionais, particulares, bem como também nas públicas (ALMEIDA, 2014).
} 
religiosas vindas da Europa. Por meio de uma educação conservadora, as congregações religiosas beneficiavam-se de certa maneira dos interesses da elite local em ter uma população feminina preparada. Para o bispo Bom Macedo Costa a influência moral e religiosa da mulher na família seria incontestável. As instituições sob a direção das congregações religiosas teria então a missão de formar a mulher virtuosa, delicada e sensível, com nobre tendência para cuidar do marido, filhos e servir a sociedade. Sem dúvida, "o processo de aburguesamento da sociedade paraense, com a expansão da economia da borracha, em fins dos oitocentos, favorecia a necessidade de instruir a mulher, conforme 'sua posição social', nos mais diversos aspectos do conhecimento humano” (BEZERRA NETO, 1998, p. 198).

Os educandários femininos no Pará, criados do final do século XIX, sob o bispado de D. Macedo Costa ${ }^{12}$, tiveram sob direção de ordens religiosas femininas diversas como: ordens das Irmãs de Santa Dorotéia e Filhas de Sant'ana que atendiam às filhas de famílias abastadas da sociedade paraense e meninas desvalidas e órfãs oriundas do interior, ou mesmo da capital, que eram encaminhadas pelo juizado de órfão.

As meninas atendidas nas instituições educativas no Pará, no início do século $\mathrm{XX}$, em que as congregações das Filhas de Sant'ana ${ }^{13}$ e das Irmãs de Santa

${ }^{12}$ D. Macedo Costa nasceu na cidade de Maragogipe na Província da Bahia, em 1830. Ordenou-se presbítero em 1857, aos 27 anos, em Paris, pelas mãos do Cardeal Arcebispo, François Nicholas Madeleine Morlot (1795-1862). Ingressou no Seminário da Bahia em 1848. Assumiu o ascebispado do Pará devido a renúncia do bispo D. José de Afonso de Moraes que esteve à frente da diocese nos anos de 1844 a 1859. Dom Macedo Costa chegou a capital do Pará em 24 de julho de 1861. Tornou-se um influente bispo no Pará e um grande defensor de uma educação feminina com participação de congregações religiosas na Amazônia.

${ }^{13}$ No ano de 1906, congregação religiosa Filhas de Sant'ana responsável pela direção do Instituto Gentil Bittencourt, desenvolveu suas atividades educativas com aproximadamente 240 meninas pobres que foram asiladas na instituição. Elas atuaram também no Orphelinato Paraense que era uma instituição que abrigava meninas órfãs estavam abandonadas na cidade de Belém. Para alcançar o progresso decorrente da República, as autoridades da capital do Pará buscava limpar a cidade do abandono de crianças e da criminalidade e prostituição. Tal iniciativa foi fortemente implementada pelo intendente Antônio Lemos. Como diz Sarges (2010, p. 20), a gestão municipal de Lemos de tornar a cidade uma pequena "Paris nos Trópicos" em decorrência da "nova ordem econômica e nova filosofia financeira nascida com a República impunham não somente a ordenação da cidade através de uma política de saneamento e embelezamento, mas também a remodelação dos hábitos e costumes sociais. Era preciso alinhar a cidade aos padrões da civilidade europeia. Desse modo, a destruição da imagem da cidade 
Dorotéia ${ }^{14}$ estiveram à frente eram educadas com a finalidade, de um lado, pelo ideário republicano se tornarem futuras mães de família, além de agregar, também, colaboração das futuras mulheres para a construção da nova pátria; de outro lado, motivado pela riqueza da economia da borracha, a oligarquia paraense buscava educar e instruir mulheres para atender às demandas dessa nova era de prosperidade na Amazônia. As congregações religiosas ${ }^{15}$ foram primordiais para a continuidade destes dois contextos pelo qual a cidade de Belém se mostrava ao mundo civilizado. Porém, não se abriam amplas possibilidades profissionais para as mulheres, pois, como afirma Rago (1985, p. 63), “a educação visava prepara-la, não para a vida profissional, mas sim, para exercer sua função essencial: a carreira doméstica, [...] torná-la uma companheira mais agradável e interessante ao homem”.

Para Bispo do Pará, Dom Macedo Costa, a Amazônia era um lugar de grande potencial econômico, porém com uma população ignorante e que precisava se tornar civilizada, e o único caminho seria cultivar a intelectualidade e os princípios morais. Portanto, para o referido religioso, a saída era elevar o nível intelectual do povo, principalmente das mulheres. Dizia ele: "se estas são más, a sociedade o será também, se boas a sociedade prosperará” (JORNAL BOA NOVA, 1877, p. 2).

desordenada, feia, promíscua, imunda, insalubre e insegura fazia parte de uma nova estratégia social no sentido de mostrar ao mundo civilizado que acidade de Belém era símbolo de progresso".

${ }^{14}$ Sob a égide de uma formação feminina, a congregação das Irmãs Dorotéias disseminaram na instituições sob sua direção uma educação religiosa e pincipalmente para atenderem às demandas do lar e da família. Além da formação de prendas domésticas e ensino primário, as educandas recebiam uma educação cristã e moral.

${ }^{15} \mathrm{O}$ trabalho das congregações religiosas na Educação Brasileira se origina do período Colonial, com os Jesuítas da Companhia de Jesus que foi a primeira congregação religiosa a desembarcar no país para instruir, educar e catequizar colonos e povos indígenas. Portanto, os Jesuítas marcaram a História da Educação brasileira ao inaugurar as atividades da Igreja Católica no setor educacional, também por instalar as primeiras escolas elementares para atender os filhos dos colonos e de indígenas e ao mesmo tempo criaram colégios superiores para educar crianças de famílias socialmente favorecidas, bem como também para formar novos religiosos (RIZZINI; RIZZINI, 2004). O monopólio da Educação ofertada pela igreja esteve concentrado na Companhia de Jesus até meados do século XVIII, quando os Jesuítas foram expulsos por Marquês de Pombal. A partir de então, novas congregações religiosas deram continuidade ao trabalho educativo dentre as quais podemos citar os Beneditinos, Carmelitas e Franciscanos que, de certa forma, aplicaram o método de ensino jesuítico em suas práticas, o qual seguidamente foi adotado pelas congregações posteriores (PE. MOURA, 2000). 


\section{A Congregação Filhas de Sant'ana na Educação feminina do Orphanato Paraense e do Instituto Gentil Bittencourt}

Pesquisadores da História da Educação estudam há alguns anos a trajetória de ordens e congregações religiosas que migraram para o Brasil, examinando o papel que elas assumem na educação brasileira como Bittencourt (2017); Leonardi (2016); Aquino (2014); Almeida (1998; 2014); Costa \& França (2016); Bezerra Neto (1998) Rizzini \& Rizzini (2004) e Marcílio (1998). Os estudos avaliam a importância da contribuição de diversas ordens e congregações para o desenvolvimento da educação feminina no Brasil, com base em estudos tanto do ponto de vista macro como micro. Os referidos autores apontam que as ordens e congregações religiosas vindas principalmente de Portugal, Itália, França e outros país da Europa marcaram, sobremaneira o sistema escolar brasileiro, ao dirigirem institutos, asilos e colégios destinados à formação Feminina.

$\mathrm{Na}$ Amazônia, em especial na capital do Pará, muitas congregações foram convidadas para atuarem no campo da saúde e da educação, como por exemplo, a congregação Filhas de Sant'ana. A obra missionária das Filhas de Sant’ana iniciou suas ações na Itália na assistência aos enfermos e abandonados. Contudo, suas atividades foram posteriormente direcionadas para o campo da educação. Ao longo do século XIX, a congregação das missionárias Filhas de Sant’ana atuaram em vários países como: Espanha, França, Chile, Bolívia entre outros.

A cidade de Belém foi o primeiro local a receber a congregação Filhas de Sant'ana no Brasil. Desembarcaram no dia 27 de outubro de 1884, lideradas pela irmã Ana Vitória Arrchetti, acompanhada por outras cinco religiosas. A convite do Bispo do Pará, Dom Antônio de Macedo Costa, as Filhas de Sant'ana vieram com a missão de servir e evangelizar a população da Amazônia. Ficaram conhecidas como "amazonas da fé". A congregação desenvolveu suas atividades no campo da saúde, educação e assistência.

Em Belém, a congregação religiosa atuou intensamente nos cuidados aos doentes. A pedido do bispo Dom Macedo Costa, as religiosas assumiram a direção do Hospital Bom Jesus dos Pobres, com o objetivo de prestar assistência aos pobres 
doentes necessitados. Em razão do cuidadoso trabalho com os doentes e reconhecimento das autoridades locais com a dedicação das religiosas Filhas de Sant'ana, outros estabelecimentos lhes foram entregues como: Hospital dos Alienados (no atendimento aos doentes mentais); Hospital Leprosário do Tucunduba (no atendimento de leprosos); Hospital Dom Luiz da Sociedade de Beneficência Portuguesa (no atendimento de doentes em geral); Hospital Domingos Freire (no atendimentos de doentes em isolamento social com tuberculose, malária, varíola, febre amarela, febre tifoide e difteria que necessitavam isolamento); Hospital São Sebastião (no atendimento de doentes de varíola e doenças venéreas). Além desses hospitais, as religiosas ainda gerenciaram o Asilo de Mendicidade, criado em 1899, pelo intendente Antônio Lemos.

No campo da educação, a congregação das Filhas de Sant'ana, com o apoio da Igreja, em especial do bispo do Pará Dom Macedo Costa, ficou responsável pela administração do Orphelinato Paraense, estabelecimento de ensino fundado em 1893 pelo então governador do Estado do Pará, Sr. Lauro Sodré, com o objetivo de educar meninas órfãs pobres e abandonadas dentro dos princípios religiosos e de educação feminina para o lar. A recondução de grupos religiosos no campo da educação tem relação direta com o movimento migratório de congregações religiosas masculinas e femininas para o Brasil, no fim do século XIX e início do século XX, pela expansão da Igreja Católica e pela intervenção dos bispos de dioceses brasileiras que tinham o apoio das elites locais (BITTENCOURT, 2017).

As religiosas da congregação das Filhas de Sant'ana passam a administrar o Orphelinato com muitas dificuldades financeiras para manter a instituição de pé e com o prestígio que já havia adquirido na sociedade paraense. Em janeiro de 1901, o Orphelinato passou a ser administrado pela intendência município no governo intendência municipal do governo de Antônio Lemos que deu todo apoio às demandas propostas pela congregação. Sob a gestão da esfera municipal, o Orphelinato passou a ser "a menina dos olhos" do intendente que reestruturou a instituição de modo a torná-la referência na formação feminina na cidade de Belém. Em março de 1906, o Orphelinato Municipal passou a chamar-se Orfanato Antônio Lemos, com a inauguração de um majestoso prédio próprio, afastado da capital, “em local espaço vasto e disposto a dar às órfãs uma educação apropriada às suas 
condições. [...] Sem prejuízo do razoável cultivo de sua inteligência e do ensino dos misteres domésticos” (ROQUE, 1996, p. 441).

Outra instituição sob a administração das Filhas de Sant'ana foi o Instituto Gentil Bittencourt, que até o final do século XIX, chamava-se Colégio Nossa Senhora do Amparo, criado em 1838, para recolher, educar e instruir meninas desvalidas a fim de se tornarem "mães de família" ou "filhas de criação". O Colégio do Amparo teve uma longa atuação com o propósito de "se constituir como um dos agentes educadores destas meninas, recolhendo-as provisoriamente do convívio direto com a sociedade, dando-lhes assistência, moralizando-as, higienizando e disciplinado-as" (SABINO, 2015, p. 103).

A mudança do Colegio Nossa Senhora do Amparo ${ }^{16}$ para a de Instituto Gentil Bittencourt aconteceu em fevereiro de 1897, no governo do Dr. José Paes de Carvalho, que decretou tal mudança para homenagear o vice-governador, Dr. Gentil Augusto de Moraes Bittencourt, pelos serviços prestados à causa pública.

No que se refere às instituições administradas pelas religiosas Filhas de Sant'ana as aulas referentes ao currículo do ensino primário eram ministradas pelas alunas normalistas, as quais estiveram presentes no cotidiano do Instituto Gentil Bittencourt e também no já extinto Colégio Perseverança, como demonstra um trecho do jornal A Palavra, que anuncia os serviços do referido Colégio o qual noticiava que: "[...] as aulas estão confiadas a talentosas professoras normalistas, seguindo o programma official” (JORNAL A PALAVRA, 1920, p. 2).

As Filhas de Sant'ana desenvolviam uma educação formativa às meninas órfãs, voltada para o princípio da civilidade, de acordo com a educação Cristã. As educandas deveriam se tornar mulheres bem formadas dentro dos princípios morais da Igreja Católica. Por essa razão que parte do conjunto de docentes da instituição eram as próprias religiosas. Atuando diretamente na educação das educandas, elas estabeleciam uma forma de controle das mentes e corpos das educandas, e principalmente prepará-las para o casamento e para a vida de esposa, de maneira a aturar no âmbito do espaço privado da casa. Portanto, a educação moral, religiosa e

\footnotetext{
${ }^{16}$ Esta instituição foi uma das primeiras e principais instituição de recolhimento de meninas órfãs e desvalida da capital do Pará, criada em 1804, pelo bispo do Pará Dom Manuel de Almeida Carvalho".
} 
de habilidades das prendas domésticas tornaria as educandas em mulheres honradas e com comportamentos de acordo com a moral cristã.

Tanto no Orfelinato Paraense quanto no Instituto Gentil Bittencourt, as religiosas Filhas de Sant'ana eram responsáveis pelo ensino das habilidades manuais femininas com aulas de pintura, desenho e flores e os chamados trabalhos de agulhas tais como: bordados e costuras. Além desses ensinamentos, as educandas tinham aulas na oficina de tipografia com o intuito de desenvolver as aptidões artísticas. No relatório de mensagem de 1907, do então governador Augusto Montenegro à assembleia legislativa do estado, há muito bem explicado que a oficina de tipografia era "uma ensino profissional, [...] afim de ensinar as alumnas que tivessem vocação para a arte, já que em algums paizes exercidas por mulheres e na qual muitas podem encontrar meio de subsistência decente e honrosa (PARÁ, 1907, p. 35). A partir de 1907, as religiosas começaram a se preocupar em educar as meninas órfãs do Gentil Bittencourt com um ofício em razão da inserção das mulheres paraenses no mercado de trabalho. Como as educandas tinham uma formação considerada de qualidade, muitas delas conseguiram empregos em atelier de costura e também em lojas de confecções de roupas, rendas e bordados e de enxovais para noivas.

As aulas de prendas domésticas estavam inseridas no cotidiano educativo nas instituições educativas, sob a responsabilidade das religiosas de Sant'ana. E no Instituto Gentil Bittencourt o ensino era dado conforme o nível de aprendizagem das alunas, onde o cronograma se organizava em duas aulas, sendo "uma das mais adeantadas, outra das principiantes", e eram "freqüentadas por todas as alumnas por turno, a excepção das menores". Nestas aulas as educandas aprendiam os primeiros pontos de costura, "de marca, algum pequeno objecto em palha, [...] $\mathrm{Na}$ aula das principiantes apprendem costura à mão, confecções de roupas, rendas e bordados fáceis". Já as aulas para as educandas mais “adeantadas se aperfeiçoam nas costuras, confecções de roupas; trabalham rendas de diversos gêneros, bordados á branco e a matiz" (INSTITUTO GENTIL BITTENCOURT, 1909, p. 9).

Muitos dos materiais produzidos nas aulas de prendas domésticas eram colocados em exposições de trabalhos manuais no formato de bazares que, em geral, ocorria na própria instituição educativa e amplamente noticiados pelo Jornal A Folha 
do Norte, para que toda a população de Belém pudessem tomar conhecimento, de um lado, da educação esmerada que as meninas do Instituto Gentil Bittencourt recebiam das religiosas; e de outro, era uma forma de adquirir recursos para o ajudar as educandas custearem suas despesas, como também com o seu dote. O zelo das congregações em relação às meninas órfãs e desamparadas estava em dar uma formação e "lhes oferecer um destino digno, ou um destino digno, ou uma colocação familiar respeitável ou distribuição de dotes a fim de atrair pretendentes para o matrimônio” (MARCÍLIO, 1998, p. 168).

As prendas produzidas pelas meninas do Gentil Bittencourt, administradas pela congregação das Filhas de Sant'ana, eram expostas em bazares anuais "dignas de elogios de quantas pessoas ali compareceram, ou para admirar a prenda artisticamente confeccionada, por mãos das gentis educandas". As notícias nos jornais referentes às exposições das educandas destacavam especialmente a qualidade das prendas confeccionadas por elas que "prendiam a attenção do espectador a distribuição feita com a simetria, o que causa uma impressão agradável. [...] Esta exposição é annual e deve ser vista por quantos se interessarem pela arte do Belo e do Bem" (JORNAL A PALAVRA, 1925, p.2). As senhoras da elite paraense costumavam prestigiar assiduamente os bazares das educandas do Instituto Gentil Bittencourt, por considerarem seus trabalhos de bordado e costura de grande qualidade, tanto que algumas educandas foram contratadas para produzirem peças manuais personalizadas.

O ensino do desenho era uma atividade artística destinada à promover as habilidades das educandas. $\mathrm{O}$ aprendizado dessa habilidade objetivava $\mathrm{O}$ desenvolvimento da inteligência, da observação e do requinte estético das educandas. De acordo com França (2007, p. 206), “essa educação compreendia o ensino do desenho nas suas mais variadas manifestações". Os trabalhos manuais cederam lugar à modelagem em gesso e à pintura, pois além de exigirem das educandas muito tempo, tinham pouca utilidade. No ano de 1909, no Instituto Gentil Bittencourt, as religiosas de Sant'ana ofertavam o ensino de desenho e pintura uma vez por semana, com três horas de aulas, a um grupo de educandas que ainda que apresentavam as habilidades. Embora houvesse interesse de grande parte das educandas para as aulas de desenho e pintura, eram poucas as que possuíam 
"verdadeira vocação artísticas; além disso o tempo" era "limitado para adestrar a mão e o espírito para serem artísticos". No mais, as educandas habilidosas submetiam seus trabalhos de desenho e pintura em uma exposição, no ano de 1909, promovida pela Diretoria da Instrução Pública do Pará e que era composta por um "jurí que concedeu um prêmio para a menina Maria Lima, consistente em uma pena de ouro, e menção honrosa à diversas outras" (RELATÓRIO DO INSTITUTO GENTIL BIT'TENCOURT, 1909, p. 8).

O ensino de habilidades para o canto e música entre as educandas permitiam uma formação estética adequada para as mulheres paraenses, sobretudo para as que conseguiam ascender na sociedade local. De certo modo, a elite local apreciava mulheres com dotes musicais por consideram habilidades femininas importante para torná-las senhoras úteis ao refinamento das famílias paraenses. No Instituto Gentil Bittencourt essas aulas eram ministradas pelo capelão da instituição. A educação feminina nessas escolas ou internatos religiosos, como o do Instituto Gentil Bittencourt, visava preservar a moral e a instrução da mulher para o lar, "procurando guardá-la dos desvios que pudessem ferir a imagem da mulher perfeita (instruída para o lar, e para o esposo)" (MANOEL, 1996, p. 86).

Até o ano de 1908, as educandas do Instituto Gentil Bittencourt não ofertava o ensino de língua estrangeira. Em 1909, sob a direção da madre superiora Tita Sbrilli, cria-se uma cadeira para o ensino de Língua Francesa, dizendo que parecia "exquisito que meninas, as quaes completam aqui o curso primário, saiam, sem conhecer nem elementos de uma língua julgada universal" (INSTITUTO GENTIL BITTENCOURT, 1909, p. 7).

Com relação à educação religiosa no Instituto Gentil Bittencourt, era ministrada pelas orações diárias e aulas de catecismo. A rotina religiosa iniciava muito cedo da manhã quando as educandas acordavam, após o banho, por volta das 6:30h, se reuniam para as orações e a missa celebrada na capela (INSTITUTO GENTIL BIT'TENCOURT, 1990, p. 18).

As Filhas de Sant'ana era uma congregação em que as religiosas procuravam dar às meninas órfãs e pensionistas tanto do Instituto Gentil Bittencourt, como o Orphelinato, uma educação feminina refinada, com o intuito de atender aos anseios da sociedade local e para torná-las futuras mães de família e boa esposa. Ademais, 
essas futuras mães que deveriam ocupar apenas o espaço do lar, precisavam dispor de uma certo capital cultural para conviver em uma sociedade em ascensão.

A formação no magistério estava presente em todas as instituições geridas pela congregação Filhas de Sant'ana. A função do magistério era vista como uma tarefa feminina, de modo que este pensamento era compartilhado pelo então governador Lauro Sodré, o qual via a mulher como ideal à função, pois não havia como não ser a

missão de ensinar confiada a mãos femininas. Si em toda a parte a mulher tem; revelado a sua aptidão especial para esse mister, tão digno della, aqui não têm sido em menor gráo as demonstrações de seu feitio moral, que a faz apta para essa tarefa (PARÁ, 1918, p. 55).

Os exames finais constituíam o processo formativo das educandas do Instituto Gentil Bittencourt. As provas eram aplicadas por professores dos grupos escolares do estado do Pará. As provas escritas, práticas e orais avaliavam o conhecimento das educandas em caligrafia, desenho, escrita, ditado, aritmética. De acordo com o desempenho das educandas, a comissão de avaliadores atribuía o resultado do julgamento em três categorias: distinção, aprovação plena e reprovação. O exame previa ainda a distribuição de prêmios para as melhores alunas, que acontecia durante a realização de festa de encerramento do ano letivo. Em geral, as festas de encerramento dessa instituição eram divulgadas na imprensa local, da presença de autoridades da Igreja e do governo, cercado de muita pompa e variadas culturais como: banda de música, peças teatrais, saraus literários e a colação de graus das educandas. Na festa de Encerramento do ano letivo do Instituto Gentil Bittencourt, em 1923, foi divulgado no Jornal A Palavra assim com as premiações e os respectivos nomes das educandas condecoradas com louvor. A matéria destacava que se encerravam "os trabalhos escolares neste conhecido educandário com belíssima festa a quem assistiram as autoridades e muitas famílias”. Destacava, ainda, as atividades da festa e que no "intervalo distribuíram-se os boletins e prêmios ás alumnas" que foram contempladas com as seguintes premiações: prêmio de distinção em estudo; prêmio de comportamento; prêmio de distinção em música, desenho e em religião (JORNAL A PALAVRA, 1923, p. 2). 
O cotidiano das educandas no Instituto Gentil Bittencourt e no Orfanato Antônio Lemos se baseava em práticas de controle comportamental, vigilância, disciplinas e códigos morais. O regime de clausura imutava a vida religiosa das educandas que enfrentavam um cotidiano de vigilância e controle disciplinares. $\mathrm{O}$ controle das atividades diárias das educandas era rigoroso e acompanhando pelas religiosas que zelavam pela ordem do espaço e da obediência. Além disso, as tarefas de contexto formativo deveriam ocorrer de maneira ordeira, com bom comportamento e postura corporal adequada.

As irmãs Filhas de Sant'ana exigiam das educandas comportamento disciplinares e, em caso de situações de indisciplinamento, elas recebiam brandas ou severas punições. Nos casos mais graves de indisciplinamento, as religiosas ordenavam a expulsão das educandas ou encaminhadas para casas de família abastarda na condição de "filhas de criação", com o objetivo de serem utilizadas para serviços domésticos ou damas de companhia. Somente com o casamento que as meninas do Gentil Bittencourt poderiam sair da instituição, aos 18 anos. Para Pimenta e França (2015, p. 262; p. 258), Antônio Lemos defendia que a mulher tinha de ser educada para o lar, aprender os afazeres domésticos, ser mãe de família boa e amorosa, além de que pudesse cuidar do marido, ou seja, "não era uma educação qualquer, pois essa mulher teria que ter uma inteligência culta"'. E afirmam as autoras: "podemos ter a dimensão do trabalho desenvolvido pelas 'Filhas de Sant'ana aqui no Pará, [...] Essas religiosas, de certa forma, contribuíram para a formação de mulheres no Brasil”".

\section{A Congregação das Irmãs Dorotéias na Educação de mulheres no Colégio Santo Antônio}

Já as religiosas da congregação Irmãs de Santa Dorotéia tiveram o Colégio Santo Antônio como instituição sob sua administração. No início da República no Pará, a formação das educandas pelas religiosas Dorotéias era bem recebida pelas famílias mais tradicionais da capital paraense, que preferiam confiar a educação de suas filhas às religiosas das referidas congregações as quais instruíam as alunas 
dentro dos padrões mais tradicionalistas. Esta questão fica evidenciada em outro trecho de uma matéria do jornal A Palavra sobre o Colégio Santo Antônio e as bodas de ouro da chegada das religiosas Dorotéias a Belém. Nesta matéria há destaque ao crescimento de entrada de alunas que "quaes se instruem na religião, nas sciencias, nas letras, nas artes e em todas as prendas que fazem de uma donzella, no presente, o enlevo dos paes e irmãos, no futuro a mãe de família verdadeiramente christã". É destacado, ainda, na matéria o zelo e os cuidados das Irmãs Dorotéias na formação primária e no ensinamento das prendas domésticas das orfansinhas "no preparo de suas collegiaes, nem um instante descuram de suas orphansinhas, que alimentam, vestem, tratam, ensinam a ler, escrever, contar, e exercitam em todos os misteres domésticos". No mais, "a medida que se desvelam as Irmãs, aparelhando-as a viverem honestamente, dentro de sua condição, sem cahir nas ciladas do mundo" (JORNAL A PALAVRA, 1927, p. 2).

A questão do cultivo da civilidade e dos valores cívico-patrióticos e da ordem também estiveram presentes no cotidiano das meninas. Todavia, a formação doméstica era o eixo de sustentação da educação feminina, considerando-se que a instrução de habilidades do gênero também se configurava como fator do que Veiga (2015) nomeou como educação estética para a civilidade.

O ensino das habilidades femininas, particularmente aquelas mais refinadas como o canto e música, possibilitariam além da educação doméstica, uma formação mais esmerada para que pudessem conviver em sociedade. Por isso, abarcar esses fatores na educação feminina também pressupunha dar educação estética pois a partir disso seria possível ofertar formação: “[...] integral e útil à família e ao lar, cujo objetivo seria ornar o espírito, despertar emoções do gozo artístico que suscitariam um estímulo para a vida espiritual e moralmente superior" (VEIGA, 2015, p. 408).

Segundo Veiga (2015), o ensino destas habilidades mais sofisticadas estava relacionado ao objetivo de formar indivíduos mais sensíveis e habilidosos, o que condizia com a mentalidade estabelecida pela República, a qual exigia que o indivíduo além de educado deveria ser dotado de cultura por meio dos trabalhos práticos, que seriam por exemplo, os trabalhos manuais femininos. Dessa forma, as práticas formativas femininas gerenciadas pelas religiosas das citadas congregações estavam inseridas nesta lógica, o que possibilitaria às futuras mulheres estarem aptas 
a frequentar a sociedade, contudo, a história mostra que a instrução mais esmerada era destinada apenas às pensionistas dessas instituições.

Além desta formação mais erudita, as religiosas desenvolviam nas educandas as habilidades manuais básicas para mulher como: bordado, costura entre outras. Em relação as Irmãs Dorotéias, o currículo da instituição administrado pelas referidas religiosas dava destaque ao ensino dos trabalhos manuais, estes que eram oferecidos desde a fundação do Colégio, de modo que o jornal A Boa Nova via estas atividades como uma arte e as denominava como parte artística, oferecendo lições de: “[...] coser, diversos pontos de marca, bordar a branco, [...] flores de panno, seda, cera, missanga e sola, pintura oriental e outras obras de mão, desenho, pintura" (JORNAL A BOA NOVA, 1877, p. 3).

Esta educação estética também esteve presente no cotidiano educativo das meninas formadas nas instituições educativas lideradas pelas religiosas de Sant'ana e Santa Dorotéia em Belém, onde de acordo com as fontes, as religiosas Dorotéias eram responsáveis pelo ensino dos dotes femininos desde os mais básicos até os mais refinados, como as aulas de canto. No que refere às religiosas de Sant'ana, a educação mais refinada também fazia parte da instrução das meninas, tendo as religiosas desta congregação à frente das lições femininas básicas e refinadas, entre as quais as aulas de canto.

As aulas de canto eram muito apreciadas pelas meninas do Colégio Santo Antônio e importante para a formação de habilidades sofisticadas e despertavam as emoções e o perfil artístico, pois permitiam às alunas uma formação delicada para reger o lar. No mais, o ensino da música, o canto coral e composição musical deveria desenvolver a inteligência e o sentimento e despertar nas educandas o interesse pelas artes (FRANÇA, 2017). As educandas recebiam o ensino de língua estrangeira que fazia parte do currículo do ensino primário desde a fundação do Colégio Santo Antônio. As Irmãs Dorotéias ofertavam o ensino de inglês e francês. Referindo-se ao ensino das línguas estrangeiras para as educandas, Veríssimo (1906, p. 170) considerava que "afora a sua utilidade prática, imediata, só lhe serviriam como fatores de educação se elas lhes ensinassem a ler, a apreciar as grandes obras".

O ensino religioso era desenvolvido pelas religiosas tanto para as órfãs como para as pensionistas, com finalidade de dar uma formação cristã e da família. 
Semanalmente havia aulas de atividades religiosas e de catecismo. As educandas recebiam a primeira comunhão ocorrida na capela do colégio (JORNAL A PALAVRA, 1916). Os valores cristãos na formação das meninas pelas Irmãs Dorotéias eram importantes para função materna e da criação dos filhos. Dom Macedo Costa publicou uma coluna no Jornal A Palavra denominada o "Deveres da Família", na qual destaca a relevância do que o conhecimento religioso para constituição das mulheres, pois, segundo ele, "ela não é só mãe, porque dá à Luz, e os alimentos a seu peito; mas é mãe sobretudo porque lhe forma o coração, e os educa para serem um dia chistãos verdadeiros e cidadãos virtuoso" (JORNAL A PALAVRA, 1916, p. 3). Dom Macedo Costa ressaltava ainda que o ensino da religião educava as meninas com parâmetros na obediência e disciplina.

No Colégio Santo Antônio, as Irmãs Dorotéias defendiam uma educação feminina de instruir as meninas pobres, órfãs e pensionistas para serem guardiãs do lar e obedientes ao marido, além de qualidades para serem mães zelosas. Enfim, a educação feminina deveria formar mulheres angelicais e moralmente virtuosas. Nas referidas instituições "as recolhidas recebiam ensino apurado, que visava a preparálas para serem mães de família e/ou empregadas domésticas instruídas e bem treinadas (MARCÍLIO, 1998, p.173).

Em uma sociedade que defendia mulheres recadas e do lar, as religiosas implementavam sob a égide das doutrina católica a preparação das educandas para o matrimônio e maternidade. Contudo, essa formação completa deveria ser refinada com aulas de bons modos e etiquetas, além de língua estrangeiras, que era fundamental para torná-las mulheres com habilidades refinadas. Segundo Costa e França (2016, p. 149), essa educação feminina defendida "pelos padres romanizadores estava na crença de que a mulher seria a peça principal para a transformação da sociedade brasileira, pela sua posição social de regente do lar doméstico".

É importante ressaltar que esse perfil feminino das educandas do Colégio Santo Antônio, sob a administração das Irmãs Dorotéias, teve a influência de Dom Antônio de Macedo Costa, bispo do Pará e fundador do Asilo e Colégio Santo Antônio. Segundo Bezerra Neto (1998), o referido bispo defendia que a mulher deveria possuir características como: abnegação, pureza, humildade e sinceridade. 
Dom Macêdo Costa produziu um conjunto de regras denominadas "deveres da família”, publicado em uma coluna do jornal A Palavra, que destacava o papel da mulher na constituição da família, de esposa que devia obediência ao seu cônjuge e, sobretudo dedicada ao lar, e ainda "[...] suportar todos os trabalhos e penas de seu estado, procurando agradar e obedecer, em tudo o que for justo, ao se marido" (JORNAL A PALAVRA, 1916, p. 3). As intenções de D. Antonio de Macedo Costa "de criar instituições educativas e tentar conquistar a hegemonia no campo da educação na Amazônia, não era apenas de combater os liberais e seu ideário de educação moderna, ele acreditava na regeneração da sociedade pela educação intelectual, moral e religiosa, principalmente pela educação das mulheres” (COSTA \& FRANÇA, 2016, p. 149).

Como se vê, a educação dada pelas Irmãs Dorotéias às meninas do Colégio Santo Antônio seguiam às orientações da Igreja Católica e aos princípios defendidos pelo eclesiástico bispo para a sociedade paraense. Ele dizia que não poderia perder de vista as virtudes da mulher, uma vez que, "o coração da mulher é admiravelmente dotado para o bem. Educar, pois, este coração, notável pela delicadeza e sensibilidade, pelas nobres tendências para o bem, é obra cuja importância a ninguém escapa (JORNAL A BOA NOVA, 1877, p. 2).

Assim como as religiosas Filhas de Sant"ana, as Irmãs Dorotéias também estimulavam as habilidades de desenho e pintura entre as educandas do Colégio Santo Antônio. Havia, ainda, exposições de desenhos promovidas pelo então governador João Antônio Luiz Coelho, que presenteava os melhores trabalhos com prêmios adquiridos na Europa, "consistentes em objetos utilizáveis na mesma arte, os quaes serão conferidos aos expositores dos melhores trabalhos (PARÁ, 1909, p. 30-31).

Com relação às festividades de encerramento do ano letivo no Colégio Santo Antônio pelas Irmãs Dorotéias, eram semelhantes ao praticado pelas religiosas Filhas de Sant'ana no Instituto Gentil Bittencourt e Orfanato Antônio Lemos antigo Orphelinato Paraense - com presença de autoridades do governo estadual e municipal e de igreja, além da presença dos pais das educandas, professores e outras autoridades especialmente convidadas. $\mathrm{Na}$ ocasião da festa, as autoridades 
diplomavam as educandas em diversas atividades curriculares, além da diplomação das alunas do Curso Comercial, que as formavam na época em "Guarda-livros".

Instrução relativa à promoção da cultura patriótica, da civilidade e da ordem também faziam parte do cotidiano de formação das meninas do Colégio Santo Antônio. As festas cívicas, como 7 de setembro, Proclamação da República e a comemoração da Adesão do Pará à Independência também seguiam uma cerimônia denominada "momento de civilidade e nacionalismo", que objetivava incentivar o patriotismo das educandas.

Com relação ao controle e disciplinamento estabelecidos pelas Dorotéias no Colégio Santo Antônio, as normas e regras deveriam ser respeitadas. O disciplinamento já era uma prática defendida na educação brasileira. Veríssimo (1906, p. 57-58), que foi Diretor da Instrução Pública no Pará, em 1891, dizia que o exercício da disciplina deveria iniciar-se na família e estendendo-se à escola desde o ensino primário, “como indispensável tirocínio para a disciplina social, base da segurança do Estado e laço da solidariedade nacional". Para as referidas religiosas, a obediência era considerada uma virtude mais exigida para a manutenção do "bem estar" das educandas, pois era uma forma de manter a harmonia entre educandas e superioras. O controle das meninas no Santo Antônio era bastante rígido e as religiosas Dorotéias apresentavam uma organização e austera administração. O Colégio Santo Antônio, comandado pelas Irmãs Dorotéias, foi um estabelecimento de ensino que seguiu padrões higiênicos e de caráter profilático no sentido de evitar doenças contagiosas e/ou epidêmicas. Portanto, "a ordenação do espaço da instituição possuía um papel importante na realização da educação das meninas, como elemento integrado à disciplinarização do comportamento das mesmas; daí o controle das entradas e saídas do Asylo/Colégio, e horários das diversas atividades" (BEZERRA NETO, 1998, p. 200).

A saída das educandas da instituição somente era permitida com o consentimento dado pela Diocese de Belém, na pessoa do bispo Dom Macedo Costa. Todavia, era permitido que as educandas deixassem as dependências da instituição somente no período de férias de final de ano e na Páscoa. 


\section{Considerações finais}

As práticas educativas realizadas nas instituições sob a gestão das congregações das Filhas de Sant'ana e Irmãs de Santa Dorotéia relatam a histórica formação destinada às meninas da cidade de Belém: a mulher como modelo de mãe e esposa, incentivadora dos bons valores e da religião no lar.

A Igreja Católica na Amazônia tinha papel importante na formação das mulheres por pregar que elas deveria ser dedicadas à família e difusoras de bons valores. Portanto, recomendava a educação voltada para o lar desde a infância enfatizando o ensino das habilidades domésticas. Assim, a participação da Igreja e a averbação de suas práticas na História da Educação foram concretizadas pelas atividades das congregações religiosas, sobretudo as femininas. Estas que, substancialmente, se ocuparam na educação e amparo aos mais necessitados e, neste caso, as meninas pobres, órfãs e pensionistas nas instituições educativas, as quais integravam um grupo que na visão da Igreja poderia se desvirtuar diante dos ares da modernidade e por isso deveriam ser resguardadas para manter sua pureza e moralidade.

Essa proposta educativa executada pelas congregações Filhas de Sant'ana e as Irmãs Dorotéias colaborou sobremaneira para formar as mães de família para a nova pátria, que se constituiu com o início da República no Pará. As religiosas de Sant'ana e Santa Dorotéia, em suas instituições, educavam as meninas nos desígnios do gênero, nos valores morais e religiosos. O contexto republicano e o ideário de progresso e civilidade em evidência na cidade de Belém, reforçavam a necessidade de uma formação feminina refinada.

As referidas congregações atenderam sobremaneira aos anseios das oligarquias no Pará na intenção de disseminar uma proposta educativa com o gerenciamento de asilos, colégios e internatos, estes que foram criados na cidade de Belém para abrigar, instruir e educar meninas órfãs e desvalidas, funcionando a partir da parceria entre Igreja, Estado e burgesia na manutenção de espaço formativos femininos na Amazônia. 
Enfim, as ações das Congregações Filhas de Sant'ana e Irmãs Dorotéias foram fundamentais para a formação de mulheres em Belém, nos anos de 1900 a 1927. No contexto da Belle Époque e do evidente crescimento populacional de mulheres no Pará existiam vários espaços considerados "perigosos” para as meninas, por esta razão era preciso evitar que elas caíssem na tentação. Para afastá-las desse mundo desviante foi necessário formar mulheres numa vida cristã e de preservação da família. Neste sentido, a educação defendida pelas congregações teriam a missão de formar mulheres que seriam modelo para os filhos e exemplo para os maridos e para a sociedade paraense.

\section{Referências}

ALMEIDA, J. S. Mulher e Educação: a Paixão pelo possivel. São Paulo: Editora UNESP, 1998.

ALMEIDA, J. S. Mulheres na Educação: missão, vocação e destino? In: SAVIANI, D. et al. O Legado Educacional do século XX no Brasil. $3^{\text {a }}$ Ed. Campinas: Autores Associados, 2014. p. $57-100$.

AQUINO, M. A diáspora das congregações feminina portuguesa para o Brasil no início do século XX: política, religião, gênero. Cadernos Pagu, n. 42, Campinas, p. 10, jan./jun., 2014.

BEZERRA NETO, J. M. As luzes da instrução: o Asylo de Santo Antonio de Belém do Pará (1870-1912). In: ACEVEDO MARIN, R. E. (org.). A Escrita da História Paraense (org.). Belém: NAEA_UFPA, 1998.

BITTENCOURT, Á. B. A era das congregações pensamento social, educação e catolicismo. Pró-Posição, Campinas, v. 28, n. 3, 2017.

COSTA, B. G.; FRANÇA, M. P. S. G. S. A. Educação de Meninas no asilo de Santo Antônio: regência das Irmãs Dorotéias sob o olhar Romanizador do Bispo D. Antônio de Macedo Costa, na Amazônia (1878-1888). Curitiba: CRV, 2016. p. 149.

FRANÇA, M. P. S. G. S. A. José veríssimo e a Educação nacional. In: ARAÚJO, S. M. S. (Orgs.). José Veríssimo: Raça, Cultura e Educação. Belém: EDUFPA, 2007, p. 206.

HAHNER, J. E. Honra e distinção. In: Nova História das mulheres no Brasil. Orgs: PINSKY, C. B; PEDRO, J. M. São Paulo: Contexto, 2018. p. 43-64.

JUBILEU, Revista. Papiro da Memória: 125 anos da presença das filhas de Sant' ana no Brasil (1884-2009). Edição comemorativa, editora Sobral- CE, 2009.

LEONARDI, P. Educação e Catolicismo. Pensar a Educação em Revista, Curitiba/Belo Horizonte, v. 2, n. 4, p. 3-23, out./dez. 2016. 
MANOEL, I. A. Igreja e Educação Feminina (1859-1910): Uma face do conservadorismo. São Paulo: EdUNE, 1996. p. 86.

MARCÍlIO, M. L. História Social da Criança Abandonada. São Paulo: HUCITEC, 1998. p. $168 ; 173$.

MOURA, P. L. D. A educação católica no Brasil. São Paulo: Loyola, 2000.

PIMENTA, A. S. F.; FRANÇA, M. P. S. G. S. A. Educação de meninas órfãs na concepção do intendente Antônio Lemos em Belém do Pará (1900-1906). In: ARAÚJO, S. M. S.; FRANÇA, M. P. S. G. S. A.; ALVES, L. M. S. A. (Orgs.). Educação e Instrução Pública no Pará Imperial e Republicano. Belém: EDUEPA, 2015, p. 263;258.

RAGO, M. Do cabaré ao lar: a utopia da cidade disciplinar. Brasil 1890/1930. Rio de Janeiro: Paz e Terra, 1985. p. 63.

RIZZINI, I.; RIZZINI, I. A institucionalização de crianças no Brasil: percurso histórico e desafios do presente. $1^{a}$ edição. São Paulo, Loyola: Ed. PUC-Rio, 2004.

RIZZINI, I.; SCHUELER, A. O Instituto do Prata; índios e missionários do Pará. In: ESTÁCIO, M. A. F.; NICIDA, L. R. A. (Orgs). História e Educação na Amazônia. Manaus: EDUA; UEA Edições, 2016. p. 77.

ROQUE, C. Antônio Lemos e sua época: história política do Pará. 2. ed. revista e ampliada. Belém: Cejup, 1996. p. 441.

SABINO, E. B. Assistência e a educação das meninas desvalidas no Colégio Nossa Senhora do Amparo na Província do Grão Pará (1860-1889). In: FRANÇA, M. P. S. G. S. A.; LOBATO, S.; N. V. S. C. (Orgs.). História da Educação na Amazônia: múltiplos sujeitos e práticas educativas. Curitiba: CRV, 2018. p. 103.

SARGES, M. N. Belém: riquezas produzindo a Belle Époque (1870-1912). 3. ed. Belém: Paka-Tatu, 2010.

SOUZA, R. F. Lições da Escola Primária. In: SAVIANI, D. et al. O legado educacional do século XX no Brasil. 3. ed. Campinas: Autores Associados, 2014.

SOUZA, R. F. História da organização do trabalho escolar e do currículo no século XX: (ensino primário e secundário no Brasil). São Paulo: Cortez, 2008.

VEIGA, C. G. Educação estética para o povo. In: LOPES, E.; FARIA, LUCIANO; VEIGA, C. 500 anos de Educação no Brasil. 5. Ed. Belo Horizonte: Autêntica, 2015. p. 408.

VERÍSSIMO, J. A Educação Nacional. Rio de Janeiro: Francisco Alves, 1906.

Relatório O Município de Belém, 1903.

Relatório de Mensagem de Governo, 1907, 1909. 
Relatório do Instituto Gentil Bittencourt, 1909.

Jornal A Palavra, 1916, 1920, 1923, 1925, 1927.

Jornal A Boa Nova, 1877, 1918.

RECEBIDO: $31 / 08 / 2020$

APROVADO: 03/10/2020

RECEIVED: 08/31/2020

APPROVED: $10 / 03 / 2020$

RECIBIDO: $31 / 08 / 2020$

APROBADO: 03/10/2020 